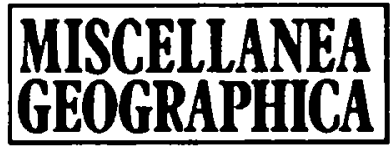

WARSZAWA 1996 VOL. 7

Andrzej Kowalczyk

\title{
SUSTAINABLE DEVELOPMENT AND PERSPECTIVES FOR DEVELOPMENT OF TOURISM IN RURAL AREAS IN POLAND
}

The development of agro-tourism can be viewed as one of the possibilities of combining the idea of sustainable development with tourist needs of industrial and post-industrial societies. An important aspect here is the mobilizing influence of tourism on agriculture and vice versa, as well as its effect on local and regional economy.

In 1989 Poland entered a period of social, political and economic transformation, which resulted in considerable changes in Polish economy, including agriculture. A decrease in export of agricultural products to Russia and the countries which came to existence after the disintegration of the USSR, and a simultaneous inflow of subsidized food products from the countries of the European Union, resulted in a serious crisis in the agricultural sector in Poland and hence considerable lowering of the standard of living in rural areas. In this situation, in 1994 the government of Poland issued two documents: „The assumptions of social and economic policy for rural areas, agriculture and food economy until the year 2000 " and "The assumptions of the development of tourist economy". In both those documents much attention has been paid to propagating the development of tourism in rural areas. Tourism is treated here first of all as a source of extra income for the farmers and also as a factor that might prevent social and economic degradation of rural areas. Therefore, the whole idea was considered to be of particular importance in the areas characterized by low-commodity agriculture (mainly the eastern regions of Poland) and by high unemployment (northern and western voivodships), which was reflected in the program which read: stimulation by way of tourism of the communes (i.e. the smallest administrative units in Poland, called gminas in Polish) situated along the border with Belarus and the Ukraine, and also with Germany.

In 1995 Polish Parliament issued an act dealing with the policy of sustainable development. Although this act has the character of a declaration only, it is expected that appropriate legal acts will follow. It should be assumed that among other things they will promote alternative forms of tourism, the development of which is much desired in rural areas. The 
necessary conditions for the development of tourist functions in rural areas in Poland are:

- preservation of family farms and a will to preserve the traditional landscape of Polish villages, their folklore, etc.;

- creation of a system of convenient credits for the people who develop tourist services in rural areas;

- investments that will improve technical infrastructure (roads, water supply systems, sewage-treatment plants, telephones) and development of services;

- increase of ecological consciousness of rural population and of local authorities (such that would prevent degradation of natural environment);

- promotion of the advantages of organizing holidays in rural areas, performed jointly by local authorities, non-governmental institutions and tourist enterprises;

- increase of the interest of urban population and of foreign tourists in spending holidays in rural areas.

One of the main factors limiting the development of tourism in rural areas is the fact that Poland, in comparison with the countries of Western Europe, is characterized by a much lower index of urbanization. $38.2 \mathrm{per}$ cent of the population inhabit the villages, and a further 12.0 per cent the towns of less than 20,000 inhabitants. This means that about a half of the population of Poland can be viewed as practically uninterested in agrotourism. In addition to that, if we take into account the fact that a considerable number of the inhabitants of large urban agglomerations and medium-sized towns are direct migrants from the villages or members of the families who have become inhabitants of towns in the first generation, the group of people interested in this form of organized rest becomes even smaller. The people of rural origin much more frequently stay with their relatives during the tourist and holiday journeys than with strangers offering them agro-tourist services. This is confirmed by the results of most recent studies. The analysis of motives of tourist trips of the population, carried out by M. Zawadzki (1995) shows that the purpose of 32 per cent of the tourists participating in 1994 in holiday journeys and of as much as $\mathbf{5 8}$ per cent of those going away for weekend trips was to visit their friends and relatives.

In view of the above, the chances for the development of agro-tourism based on Polish customers are relatively small and limited to the most attractive areas only. There are better chances for developing this kind of activity based on foreign customers. As shown by the investigations carried out by W. Bartoszewicz (1994), 9.5 per cent of foreign tourists spent their holidays in rural areas, and in the case of the tourists from Germany, as much as 15.6 per cent of those surveyed declared their stay in rural areas.

The investigations into the possibilities of development of tourism in rural areas in Poland, carried out in recent years, have shown that local 
population is considerably interested in developing agro-tourist services. However, it should be noted that this interest is much varied and results, among other things, from the tradition of rendering tourist services. The studies carried out in the spring of 1995 in four regions of Poland (Tourism in rural areas of Poland, 1995) have shown that the greatest readiness for rendering tourist services can be found in the commune Bukowina Tatrzańska, situated close to the Tatra Mountains (Table 1) where an imposing 80 per cent of respondents either are already rendering tourist services or are going to do so. A strong interest in developing tourist services in this part of Poland results not only from longtime tradition of receiving tourists, but also from economic necessity, as the surface configuration, poor soils, unfavourable climate, and above all the fact that in Poland the farms are extremely small-sized, largely delimit the possibilities of development of agriculture. It is also worth noting that in the other communes studied (see Table 1) the percentage of the people interested in developing tourist services remained on a similar level, although they were situated in different parts of Poland

Table 1

The readiness of inhabitants of selected communes (gminas) for developing tourist services (spring 1995)

\begin{tabular}{|l|c|c|}
\hline \multicolumn{1}{|c|}{ Commune (gmina) } & Voivodship & $\begin{array}{c}\text { Per cent of respondents } \\
\text { interested in developing tourist services }\end{array}$ \\
\hline Bukowina Tatrzańska $(\mathrm{n}=134)$ & Nowy Sącz & 80 \\
\hline Chmielno $(\mathrm{n}=102)$ & Gdańsk & 29 \\
\hline Krasnobród $(\mathrm{n}=221)$ & Zamość & 32 \\
\hline Eagów $(\mathrm{n}=\mathbf{1 7 9 )}$ & Zielona Góra & 25 \\
\hline
\end{tabular}

As already mentioned, the main factor speaking in favour of the development of tourism in rural areas in Poland is a drive towards improving the economic situation in the areas where agriculture is in decline, taking into account the assumptions resulting from the concept of sustainable development.

The investigations carried out in different regions of Poland have shown that tourism exerts a positive influence on local economy. For instance, according to the inhabitants of the communes situated in the valleys of two big rivers, the Bug and the Pilica (an opinion survey carried out jointly in $10 \mathrm{com}-$ munes), a favourable influence of tourism on the development of local economy was declared by, respectively, 98 per cent and 67 per cent of the respondents (Tourism in rural areas of Poland, 1995). According to the people surveyed, the development of tourism results in the growth of income of commune budgets (86\% and almost $71 \%$ answers) and of local population (over $77 \%$ and $36 \%$ of answers), and also exerts a favourable effect on cultural development of rural areas (almost $65 \%$ and over $87 \%$ of answers).

It should however be noted that a large number of respondents notice in tourism not only economic advantages, but also a considerable threat to 
natural environment, particularly in the form of littering the neighbourhood (over $44 \%$ of answers of the people surveyed in the Bug valley communes and as much as $82 \%$ of those surveyed in the Pilica valley communes) and polluting surface waters (over $26 \%$ and $14 \%$ of answers, respectively).

Local authorities are also interested in developing tourist functions. The studies carried out in the spring of 1995 in 839 rural communes (39\% of all rural communes in Poland) have shown that in 44 per cent of the analyzed
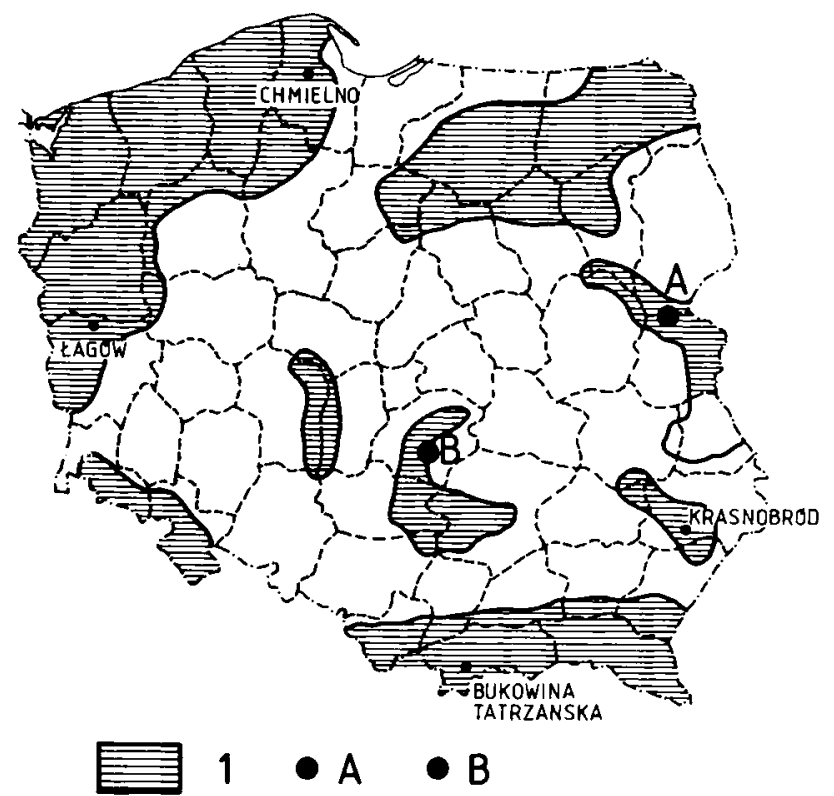

$F_{k}$ 1. Optimal areas for the development of agro-tourism in Poland A - area of investigation in the Bug valley;

$B$ - area of investigation in the Pilica valley communes tourism is treated as a principal trend of development. In 42 per cent of the communes the development of tourist functions has been included in the official programs of development, which have been accepted by local authorities. In 28 per cent of the communes investments are being introduced aimed at improving the conditions of rendering tourist services, whereas in 13 per cent of the communes tourism is already a significant source of income (Tourism in rural areas of Poland, 1995).

Summing up what was said above, it can be concluded that although Poland has good conditions for the development of tourism in rural areas, and the authorities openly declare their support for the concept of sustainable development, the chances for the development of alternative tourism are rather limited. First of all, the degree of urbanization of the Polish population is relatively low, as a result of which there is smaller interest (in comparison with the countries of Western Europe) in spending holidays in rural conditions. Secondly, Poland is a country characterized by strong differentiation of tourist values - in some regions one can expect further strengthening of tourist functions, in others they may not appear at all. The greatest possibilities for the development of tourism in rural areas occur in mountainous and submontane areas, in the lake districts and in some regions of eastern and western Poland. In those regions, apart from typical agro-tourism (family holidays at farmersł houses) one can also expect the 
development of qualified tourism, concentrated mainly on getting acquainted with historical and architectural monuments of the area, with its folk culture (including ethnic minorities), and the like. The development of ecological form of tourism is also possible. Thirdly, in order to develop tourism in rural areas it is necessary to carry out certain investments, such as to improve road network and water supply system, to build sewage-treatment plants, etc. It is also necessary to introduce convenient credits for the people wishing to render tourist services. Taking into account all limitations mentioned above, it seems that a favourable factor for further development of tourism in rural areas is the interest of the authorities (both central and local) and of the inhabitants themselves in developing tourist services, while being aware of the possible threats which may result from uncontrolled inflow of tourists.

\section{REFERENCES}

B artoszewicz W., 1994, The aims, motives and forms of visiting Poland in 1993, Institute of Tourism, Warszawa, typescript.

Tourism in rural areas of Poland. Research commissioned by PHARE TOURIN II Program. Research team: Dziemianowicz W., Hryniewicz J., Jałowiecki B., Kowalczyk A. - projekt manager, Mync A., Swianiewicz P., Wojciechowska J., Zarycki T., editor B. Jałowiecki, European Institute of Regional and Local Development, Warsaw University, 1995.

Zawadzki M., 1995, The journeys of Poles in 1994, Institute of Tourism, Warszawa, typescript. 
